\title{
Pregnancy on Bicornuate Unicollis Uterus: Diagnosis, Management and Prognosis in Underprivileged Areas: About a Case, Yaoundé-Cameroon
}

\author{
Armand Kamga Talom ${ }^{*}$, Felix Essiben ${ }^{1,2}$, Kingsley Sama Ombaku1, Forbang Ako3, \\ Esther Ngo Um Meka1,4 \\ ${ }^{1}$ Department of Obstetrics and Gynaecology, Faculty of Medicine and Biomedical Sciences, University of Yaounde I, \\ Yaounde Cameroon \\ ${ }^{2}$ Yaounde Central Hospital, Yaounde, Cameroon \\ ${ }^{3}$ Department of Medical Imaging and Radiology, Faculty of Medicine and Biomedical Sciences, University of Yaounde I, \\ Yaounde Cameroon \\ ${ }^{4}$ Yaounde Gyneco-Obstetric and Pediatric Hospital, Yaounde, Cameroon \\ Email: ^kamtalar@gmail.com, essibenx@yahoo.com, sokingsley@yahoo.com, estherum@yahoo.fr
}

How to cite this paper: Kamga Talom, A., Essiben, F., Ombaku, K.S., Ako, F. and Ngo Um Meka, E. (2021) Pregnancy on Bicornuate Unicollis Uterus: Diagnosis, Management and Prognosis in Underprivileged Areas: About a Case, Yaoundé-Cameroon. Open Journal of Obstetrics and Gynecology, 11, 602-609.

https://doi.org/10.4236/ojog.2021.115056

Received: March 10, 2021

Accepted: May 22, 2021

Published: May 25, 2021

Copyright $\odot 2021$ by author(s) and Scientific Research Publishing Inc. This work is licensed under the Creative Commons Attribution International License (CC BY 4.0).

http://creativecommons.org/licenses/by/4.0/

\begin{abstract}
Background: A bicornuate uterus is a relatively common and often asymptomatic congenital uterine malformation. Objective: The aim of this work is to highlight the diagnostic difficulty in this case, as well as its therapeutic and prognostic aspects. We report here the case of a young girl carrying a pregnancy on an undiagnosed unicollis bicornuate uterus, which was initially diagnosed as an unruptured ectopic pregnancy. Conclusion: The bicornuate uterus still poses diagnostic difficulties, especially in disadvantaged populations due to the poor accessibility of diagnostic means.
\end{abstract}

\section{Keywords}

Bicornous Uterus, Cameroun, Diagnosis, Pregnancy, Prognosis

\section{Introduction}

Malformations of the female genital tract are polymorphous in nature. The definitive diagnosis of these malformations is essentially para-clinical, using ultrasound, hysterosalpingography, hysterosonography, magnetic resonance imaging and even endoscopy. Several authors have evaluated the diagnostic accuracy of 
these different diagnostic methods. One of the problems that this patient poses for us is that she has a very low socio-economic status and in a country like ours where there is no social security, she does not have the possibility of having recourse to quality care at tertiary hospitals. In addition, the radiologist who performed the ultrasound in the neighbouring hospital where she was transited failed to diagnose this malformation. It is therefore essential to ensure the continuous training of health care providers for optimal patient care.

\section{Patient and Observation}

We report the case of a pregnancy on an unrecognised unicervical bicorneal uterus, in a 19 year old girl, G2P1000, single, unemployed and without primary education, orphaned. She presented with a past history of menstrual disorders, and a term vaginal delivery eighteen months earlier. She delivered a life male baby who weighed $2700 \mathrm{~g}$ at birth who died at two months of age from and unknown cause.

She was referred to us from a neighbouring hospital centre for better management of a non ruptured ectopic pregnancy (NREP) at a gestational age of nine weeks and one day of amenorrhea Operative laparoscopy had been proposed but could not be done due to lack of financial means.

Laboratory workup done at the referring hospital revealed a plasma $\beta$-HCG level of $18,760 \mathrm{IU} / \mathrm{L}$, which is a contraindication to medical management.

When we received the patient, she complained of pelvic pains which were more severe on the left side and mild per vaginal bleeding. She had blood pressure readings of 110/80 mmHg, pulse rate of 85 beats per minute and temperature of 37 Degree Celcius, respiratory rate of 20 cycles per minute. The conjunctivae were pink. The abdomen was undistended, mobile with respiration. We noticed a marked abdominal tenderness on palpation in the left iliac fossa with a mass of about $5 \mathrm{~cm}$ on the long axis. There was no rebound umbilical tenderness and no flank dullness. On gynaecological examination, sterile speculum exam, the cervix appeared normal on gross view with bluish discoloration, and mild endocervical bleeding. Digital vaginal exam revealed a posterior, long and closed cervix with left cervical motion tenderness. On bimanual pelvic exam, the uterus appeared normal in size and there was a tender left adnexal mass. There was no bulge on the posterior fournix suggesting a collection in the Douglass pouch. We concluded to a left unruptured ectopic pregnancy at nine weeks and one day of amenorrhea.

Initial management consisted of emergency laparotomy after counselling. The preoperative assessment was normal.

The findings of the emergency laparotomy were: A unicervical bicorn uterus with a deviated left hemi-uterus which was located in the left iliac fossa, increased in volume as $08 \mathrm{AW}$ suggesting an intrauterine pregnancy, the right hemi-uterus was of normal size. The right and left fallopian tubes and ovaries were macroscopically normal (Figure 1 and Figure 2). There was no haemoperitoneum and there were no pelvic adhesions.

The per operative procedures consisted of: Reinsertion of the uterus into the pelvic cavity and plane-by-plane parietal closure. We immediately put the 


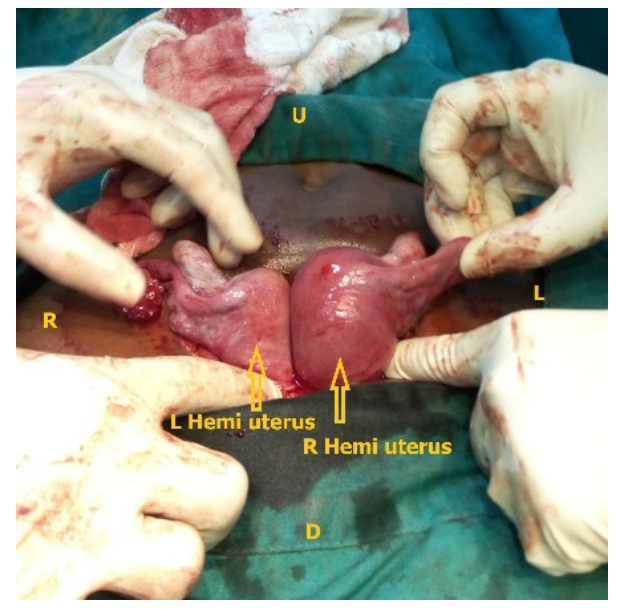

Figure 1. Exposure of the left hemiuterus uterus carrying the pregnancy. Legend: $\mathbf{R}=$ Right, $\mathrm{L}=$ Left, $\mathrm{U}=\mathrm{Up}, \mathrm{D}=$ Down.

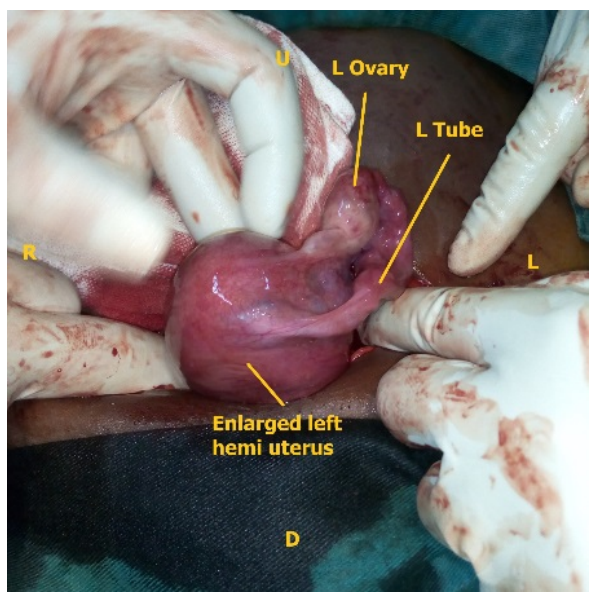

Figure 2. Annexes of the left hemi-uterus. Legend: $\mathbf{R}=$ Right, $\mathrm{L}=\mathrm{Left}, \mathbf{U}=\mathrm{Up}, \mathbf{D}=$ Down.

patient on delayed progesterone and planned to do a control pelvic ultrasound on $\mathrm{D} 5$ post-operatively.

Postoperative follow-up: The postoperative follow-up was marked by the occurrence of abundant pervaginal bleeding with a clot on day 4 , prompting a pelvic ultrasound on day 5 in favour of a complete abortion (Figure 3 and Figure 4). A dressing was applied and progesterone was stopped. Counseling was done on obstetric pathology and prognosis. The patient was discharged on Day 6.

\section{Discussion}

The actual prevalence of uterine malformations remains unclear because many abnormalities are unknown in routine clinical practice. However, uterine malformations have been reported in $7 \%$ of the general population, $7 \%$ in the infertile population, and $18 \%$ of patients with repeated miscarriages [1]. A bicornuate uterus is the result of a defect in the fusion of the two Müllerian ducts. The degree of separation of the organ is variable. A distinction is made between 


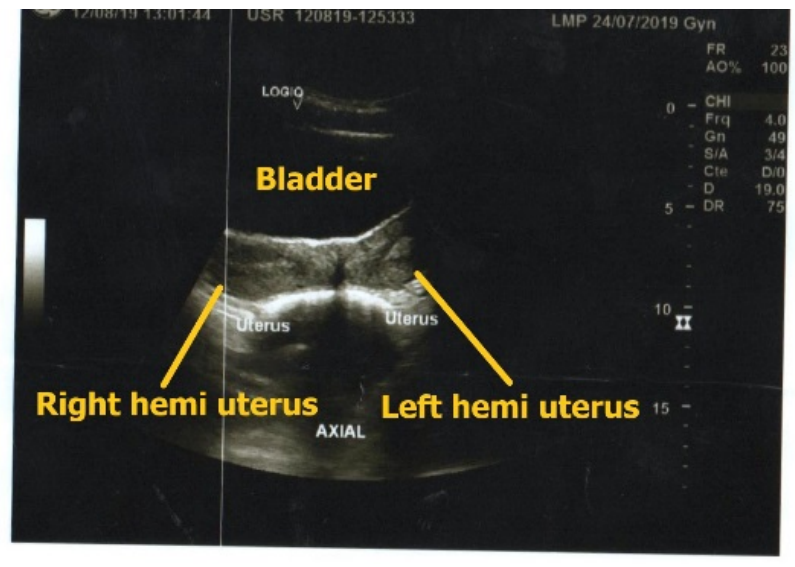

Figure 3. Axial section of the 2 hemi uterus.

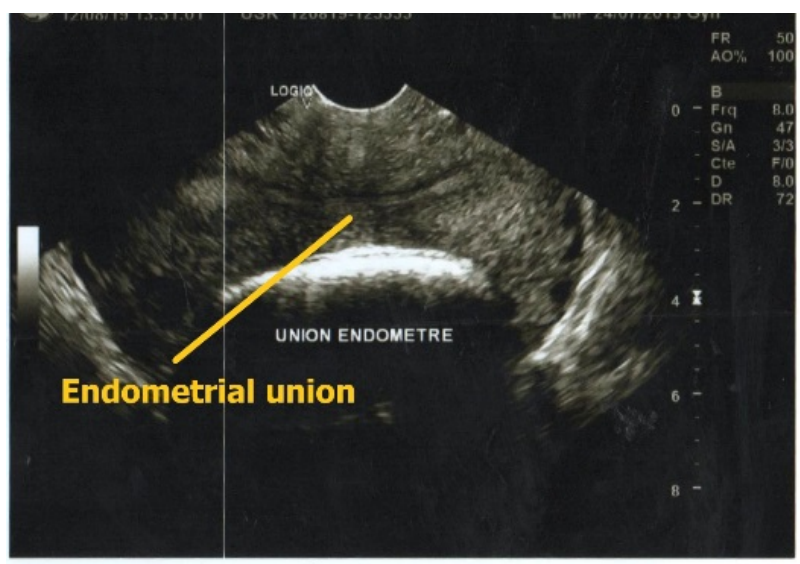

Figure 4. Longitudinal section of the 2 hemi uteri.

unicervical bicorn uteri and bicervical bicorn uteri. The overall prevalence of bicorn uteri is $0.3 \%$ and accounts for $10 \%$ of all uterine malformations [1] [2].

The identification and classification of uterine malformations is of threefold interest: the treatment of symptoms, the distinction of abnormalities which carry a high risk of obstetrical complications, and finally the differentiation of malformations which require a surgical approach by laparotomy or endoscopy. Several classifications have been described [3] [4] [5] [6]. The American Fertility Society (AFS) classification, formulated in 1988, is the most widely used because it is of therapeutic interest [5]. It classifies malformations into 7 main groups: 1) agenesis and hypoplasia, 2) unicorn uteri, 3) didelphic uteri, 4) bicorn uteri, 5) septate uteri, 6) arcuate uteri, and 7) abnormalities related to diethylstilbestrol exposure syndrome. However, there is a recent classification; that of the European Society of Human Reproduction and Embryology (ESHRE)/European Society for Gynaecological Endoscopy (ESGE) formulated in 2013, proposing a classification system that overcomes the perceived inadequacies of the AFS classification. It classifies malformations into 6 main groups: U0: normal uterus, U1: dysmorphic uterus, U2: septe uterus, U3: bicorporeal uterus, U4: hemiuterus, U5: non-plastic cases, and U6: unclassified cases [7] [8]. Based on the initial 
clinical assessment and intraoperative findings, our patient had a type (4) uterus according to the AFS and the ESHRE/ESGE.

The diagnosis of a bicorneal uterus can be made with hysterosalpingography (HSG), 2 or 3-dimensional hysterosonography (HSN), MRI and diagnostic hysteroscopy. The HSG image shows two widely separated horns, each of which is fusiform and ends in a simple fallopian tube [2]. Although there is no consensus, the angle between the horns is usually $>105^{\circ}$. However, the sensitivity of HSG is low at 55\% for diagnostic differentiation between a bicorneal uterus and a septate uterus because it does not assess the external cutting of the uterus. This sensitivity is all the lower as the angle between the 2 uterine cavities is $\leq 75^{\circ}$. In this case the diagnosis of a septate uterus is highly suggestive [9]. Studies have evaluated the accuracy of sonography, HSG, HSN with saline infusion, diagnostic hysteroscopy and laparoscopy combined with hysteroscopy in differentiating between a septate uterus and a bicorneal uterus. HSN with saline infusion is more sensitive (100\%) compared to diagnostic hysteroscopy alone (81\%) and HSG (81\%) [10] [11] [12] [13]. Another study comparing HSN with 3-dimensional saline infusion and 3-dimensional sonography compared to HSN with 2-dimensional saline infusion and 2-dimensional sonography indicated a respective sensitivity for the diagnosis of the bicorne uterus of $100 \%$ versus $97 \%$. This suggests that 3-D technology is a better to differentiate the bicornuate uterus from a septate uterus [10]. In our patient, no morphological diagnosis had been made beforehand in her non-pregnant period, as the indication had never been made before. In our patient, no morphological diagnosis had been made beforehand in her non-pregnant period, as the indication had never been made before. Moreover, for the current pregnancy, the sonography carried out suggested an inaccurate diagnosis which motivated the current treatment.

Surgical management of the bicorneal uterus is not indicated in the majority of patients. It is currently reserved only for those who have late abortions or repeated premature deliveries. Our patient did not have this past history. Historically, the first surgery on the bicornuate uterus was performed by Paul Strassman in 1907. This surgery was called Strassman's metroplasty, the approach was vaginal and consisted of incising and bringing together the two cavities of the bicorn uterus. Techniques using the abdominal approach were then described, usually starting with a medial infiltration of vasopressin from each horn [14]. An incision is made $1 \mathrm{~cm}$ from the right horn, extending $1 \mathrm{~cm}$ from the left horn. Then the myometrium and serosa are carefully sutured in 2 planes, anterior and posterior, avoiding the endometrium [15] [16]. However, this approach is subject to significant blood loss and a high rate of post-operative infection adhesions. These complications have led to the more recent development of laparoscopic metroplasty techniques [17] [18] [19] [20]. Given our patient's pregnancy status, we did not consider performing an intraoperative metroplasty.

In terms of obstetrical prognosis, the bicorneal uterus has no effect on fertility but it predisposes to first and second trimester abortions (36\% to $60 \%$ of cases) [21] [22] [23]. A systematic review of the obstetrical outcome of all women with 
Mullerian anomalies found a significant association of second trimester (14 - 22 weeks) abortions in those with a bicorneal uterus [24] [25]. Other studies have reported cases of fetal malpresentation, intrauterine growth retardation, and premature birth (19\% to $23 \%)$, the latter correlated with the degree of cavity separation [21] [22] [26]. In the case of our patient, she had a first trimester abortion. Strassman's metroplasty improves birth rates. However, one report suggests that this rate improves only modestly (65\% to $85 \%)$ with surgical repair. Another report where in another report, the foetal survival rate increased from $0 \%$ to $80 \%$ after surgical correction [27] [28] [29]. Cervical incompetence has also been found in a number of cases where cerclage has been shown to be effective in preventing premature births [30]. Our patient actually had a threatened abortion that progressed to a complete abortion. To improve the obstetrical prognosis of our patient, we recommended metroplasty by laparoscopy or laparotomy, depending on the financial means available.

\section{Conclusion}

Congenital uterine malformations, particularly bicorn uteri, are relatively common and often asymptomatic. They still pose diagnostic difficulties in our context, particularly in disadvantaged people due to the poor accessibility of diagnostic means. These malformations should be sought in the presence of primary amenorrhoea, abdominal pain, repeated miscarriages and in certain unfavourable obstetrical outcomes. The bicornuate uterus can bring a pregnancy to term. This is why it is better to detect it for a better follow-up of the pregnancy and a good prognosis of delivery.

\section{Authors' Contributions}

The authors of the manuscript have read and approved the contents of the manuscript. All authors also declare that they have read and approved the final version of the manuscript.

\section{Conflicts of Interest}

Authors do not declare any conflict of interest.

\section{References}

[1] Saravelos, S.H., Cocksedge, K.A. and Li, T.C. (2008) Prevalence and Diagnosis of Congenital Uterine Anomalies in Women with Reproductive Failure: A Critical Appraisal. Human Reproduction Update, 14, 415-429. https://doi.org/10.1093/humupd/dmn018

[2] Troiano, R.N. and McCarthy, S.M. (2004) Mullerian Duct Anomalies: Imaging and Clinical Issues. Radiology, 233, 19-34. https://doi.org/10.1148/radiol.2331020777

[3] Musset, R. and Belaich, J. (1964) Nécessité d'une classification globale des malformations utérines. In: XXIIes Assises Françaises de Gynécologie, Masson, Paris.

[4] Buttram, V. and Gibbons, W. (1979) Mullerian Anomalies: A Proposed Classification: An Analysis of 144 Cases. Fertility and Sterility, 32, 40-46. 
https://doi.org/10.1016/S0015-0282(16)44114-2

[5] (1988) The American Fertility Society Classifications of Adnexal Adhesions, Distal Tubal Occlusion, Tubal Occlusion Secondary to Tubal Ligation, Tubal Pregnancies, Müllerian Anomalies and Intrauterine Adhesions. Fertility and Sterility, 49, 944955. https://doi.org/10.1016/S0015-0282(16)59942-7

[6] Acien, P. and Acien, M.I. (2011) The History of Female Genital Tract Malformation Classifications and Proposal of an Updated System. Human Reproduction Update, 17, 693-705. https://doi.org/10.1093/humupd/dmr021

[7] Grimbizis, G.F., Gordts, S., Di Spiezio Sardo, A., et al. (2013) The ESHRE-ESGE Consensus on the Classification of Female Genital Tract Congenital Anomalies. $G y^{-}$ necological Surgery, 10, 199-212. https://doi.org/10.1007/s10397-013-0800-X

[8] Grimbizis, G.F., Di Spiezio Sardo, A., Saravelos, S.H., et al. (2016) The Thessaloniki ESHRE/ESGE Consensus on Diagnosis of Female Genital Anomalies. Gynecological Surgery, 13, 1-16. https://doi.org/10.1007/s10397-015-0909-1

[9] Reuter, K.L., Daly, D.C. and Cohen, S.M. (1989) Septate versus Bicornuate Uteri: Errors in Imaging Diagnosis. Radiology, 172, 749-752.

https://doi.org/10.1148/radiology.172.3.2528160

[10] Ludwin, A., Pityński, K., Ludwin, I., et al. (2013) Two- and Three-Dimensional Ultrasonography and Sonohysterography versus Hysteroscopy with Laparoscopy in the Differential Diagnosis of Septate, Bicornuate, and Arcuate Uteri. Journal of Minimally Invasive Gynecology, 20, 90-99. https://doi.org/10.1016/j.jmig.2012.09.011

[11] Abo Dewan, K.A., Hefeda, M.M. and ElKholy, D.G. (2014) Septate or Bicornuate Uterus: Accuracy of Three-Dimensional Trans-Vaginal Ultrasonography and Pelvic Magnetic Resonance Imaging. The Egyptian Journal of Radiology and Nuclear Medicine, 45, 987-995. https://doi.org/10.1016/j.ejrnm.2014.04.001

[12] Faivre, E., Fernandez, H., Deffieux, X., et al. (2012) Accuracy of Three-Dimensional Ultrasonography in Differential Diagnosis of Septate and Bicornuate Uterus Compared with Office Hysteroscopy and Pelvic Magnetic Resonance Imaging. Journal of Minimally Invasive Gynecology, 19, 101-106.

https://doi.org/10.1016/j.jmig.2011.08.724

[13] Ludwin, A., Ludwin, I., Banas, T., et al. (2011) Diagnostic Accuracy of Sonohysterography, Hysterosalpingography and Diagnostic Hysteroscopy in Diagnosis of Arcuate, Septate and Bicornuate Uterus. Journal of Obstetrics and Gynaecology Research, 37, 178-186. https://doi.org/10.1111/j.1447-0756.2010.01304.x

[14] Strassmann, E.O. (1952) Plastic Unification of Double Uterus; a Study of 123 Collected and Five Personal Cases. American Journal of Obstetrics and Gynecology, 64, 25-37. https://doi.org/10.1016/S0002-9378(16)38732-4

[15] Alborzi, S., Asefjah, H., Amini, M., et al. (2015) Laparoscopic Metroplasty in Bicornuate and Didelphic Uteri: Feasibility and Outcome. Archives of Gynecology and Obstetrics, 291, 1167-1171. https://doi.org/10.1007/s00404-014-3520-1

[16] Nishida, M., Otsubo, Y., Arai, Y., et al. (2016) Difference in Reproductive Performance between Two Subtypes of Bicornuate Uterus. Archives of Gynecology and Obstetrics, 293, 1335-1338. https://doi.org/10.1007/s00404-016-4047-4

[17] Bhagavath, B., Behrman, E., Salari, B.W., et al. (2015) Metroplasty to Treat Chronic Pelvic Pain Resulting from Outflow Tract Mullerian Anomalies. American Journal of Obstetrics and Gynecology, 213, 871e1-3.

https://doi.org/10.1016/j.ajog.2015.09.007

[18] Speroff, L. and Fritz, M. (2005) Clinical Gynecologic Endocrinology and Infertility. 
7th Edition, Lippincott Williams \& Wilkins, Philadelphia.

[19] Rousset, P., Raudrant, D., Peyron, N., et al. (2013) Ultrasonography and MRI Features of the Mayer-Rokitansky-Küster-Hauser Syndrome. Clinical Radiology, 68, 945-952. https://doi.org/10.1016/j.crad.2013.04.005

[20] Acien, P. (1992) Embryological Observations on the Female Genital Tract. Human Reproduction, 7, 437-445. https://doi.org/10.1093/oxfordjournals.humrep.a137666

[21] Reichman, D., Laufer, M.R. and Robinson, B.K. (2009) Pregnancy Outcomes in Unicornuate Uteri: A Review. Fertility and Sterility, 91, 1886-1894.

https://doi.org/10.1016/j.fertnstert.2008.02.163

[22] Rackow, B.W. and Arici, A. (2007) Reproductive Performance of Women with Müllerian Anomalies. Current Opinion in Obstetrics and Gynecology, 19, 229-237. https://doi.org/10.1097/GCO.0b013e32814b0649

[23] Zyla, M.M., Wilczynski, J., Nowakowska-Glab, A., et al. (2015) Pregnancy and Delivery in Women with Uterine Malformations. Advances in Clinical and Experimental Medicine, 24, 873-879. https://doi.org/10.17219/acem/23171

[24] Chan, Y.Y., Jayaprakasan, K., Tan, A., et al. (2011) Reproductive Outcomes in Women with Congenital Uterine Anomalies: A Systematic Review. Ultrasound in Obstetrics \& Gynecology, 38, 371-382. https://doi.org/10.1002/uog.10056

[25] Venetis, C.A., Papadopoulos, S.P., Campo, R., et al. (2014) Clinical Implications of Congenital Uterine Anomalies: A Meta-Analysis of Comparative Studies. Reproductive BioMedicine Online, 29, 665-683.

https://doi.org/10.1016/j.rbmo.2014.09.006

[26] Takami, M., Aoki, S., Kurasawa, K., et al. (2014) A Classification of Congenital Uterine Anomalies Predicting Pregnancy Outcomes. Acta Obstetricia et Gynecologica Scandinavica, 93, 691-697. https://doi.org/10.1111/aogs.12400

[27] Papp, Z., Mezei, G., Gavai, M., et al. (2006) Reproductive Performance after Transabdominal Metroplasty: A Review of 157 Consecutive Cases. The Journal of Reproductive Medicine, 51, 544-552.

[28] Rechberger, T., Monist, M. and Bartuzi, A. (2009) Clinical Effectiveness of Strassman Operation in the Treatment of Bicornuate Uterus. Ginekologia Polska, 80, 88-92.

[29] Sugiura-Ogasawara, M., Ozaki, Y., Katano, K., et al. (2011) Uterine Anomaly and Recurrent Pregnancy Loss. Seminars in Reproductive Medicine, 29, 514-521. https://doi.org/10.1055/s-0031-1293205

[30] Yassaee, F. and Mostafaee, L. (2011) The Role of Cervical Cerclage in Pregnancy Outcome in Women with Uterine Anomaly. Journal of Reproduction \& Infertility, 12, 277-279. 